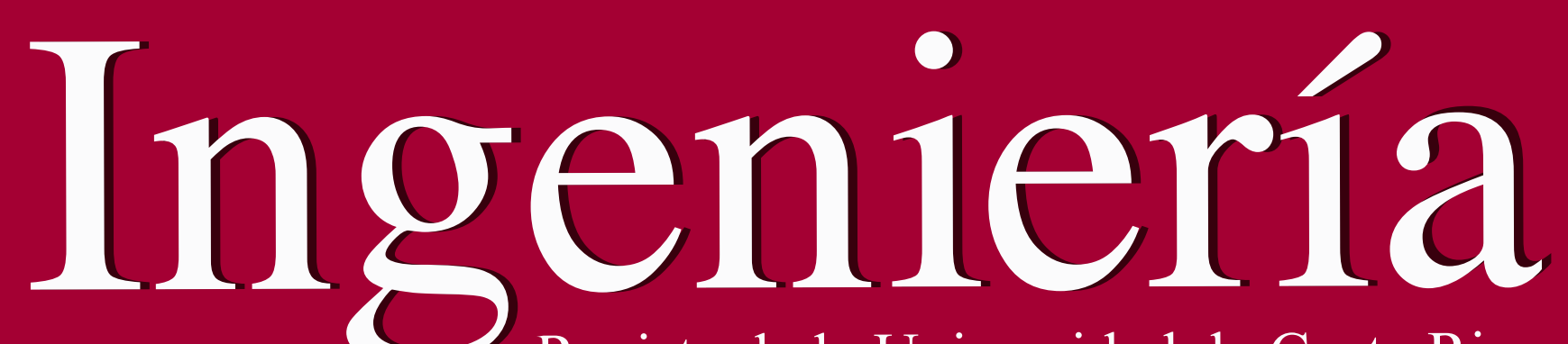

Revista de la Universidad de Costa Rica JULIO / DICIEMBRE 2020 - VOLUMEN 30 (2)

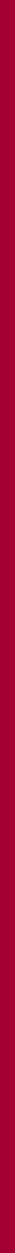




\title{
Experimental evaluation of the effect of spatial position on the power of a $5 \mathrm{~W}$ LED \\ Evaluación experimental del efecto de la posición espacial en la potencia de un LED 5W
}

\author{
María Paula Gutiérrez Domínguez, \\ Pontificia Universidad Javeriana, Bogotá, Colombia \\ mariapaula.gutierrez@outlook.com \\ ORCID: https://orcid.org/ORCID: https://orcid.org/0000-0001-6106-5543 \\ Diana Elizabeth Ramírez López \\ Pontificia Universidad Javeriana, Bogotá, Colombia \\ di.ramirez01@javeriana.edu.co \\ ORCID: https://orcid.org/0000-0002-9503-5462 \\ Ricardo Otero-Caicedo \\ Pontificia Universidad Javeriana, Bogotá, Colombia \\ r.otero@javeriana.edu.co \\ ORCID: https://orcid.org/0000-0002-0358-8538
}

Recibido: 28 de noviembre 2019

Aceptado: 27 de febrero 2020

\begin{abstract}
This experiment evaluates the effect of the spatial position on the power of a 5W LED, which was obtained using a radiometer. For this purpose, the radiant flow emitted by the LED was arranged and; taken at different positioning angles and distances from the sensing equipment. Statistical analysis for the validation of the obtained data was checked against the values provided by the manufacturer according to the specification sheet. Finally, the increase in tilt angle and distance resulted in a loss of radiant flow emitted by the LED by $99 \%$.
\end{abstract}

Keywords:

Spatial position, LED, power, experimental method

\section{Resumen}

En este experimento, se realiza la evaluación del efecto de la posición espacial en la potencia de un LED de 5W, la cual se obtuvo utilizando un radiómetro. Para tal fin se dispuso del flujo radiante emitido por el LED, tomado en diferentes ángulos de posicionamiento y la distancia del mismo con respecto al equipo de detección. El análisis estadístico para la validación de los datos obtenidos se cotejó con los valores 
DOI 10.15517/ri.v30i2.39823 Ingeniería 30 (2): 120- 132, julio-diciembre, 2020. ISSN: 2215-2652. San José, Costa Rica

proporcionados por el fabricante según la hoja de especificaciones. Finalmente, se obtuvo que el aumento del ángulo de inclinación y la distancia generan una pérdida del flujo radiante emitido por el LED en un $99 \%$.

Palabras clave:

Posición espacial, LED, potencia, estudio experimental 


\section{INTRODUCTION}

Progress in solid-state light devices has led to the replacement of incandescent lamps with Lightemitting diodes, known as LEDs, which have as principle the effect of electroluminescence. This is based on the light emitted by the device through the transformation of electrical energy (Rigutti \& Tchernycheva, 2013). LEDs have been applied as light sources in countless areas, such as nanotechnology, computing, bioengineering, medicine, among others (Noori, Mahbub, Dvorák, Lucieer \& Macka, 2018).

LEDs offer a better alternative to traditional light sources, in terms of low cost, smaller size, longer service life, higher light power, and energy saving (Schubert \& Kyu, 2005). Recent developments have shown that most white LEDs are typically $30 \%$ efficient, while some have reached $40 \%$. Although LEDs are known as the most efficient lighting source, a significant amount of electrical energy supplied is still converted to heat. Approximately $60 \%-70 \%$ of lost energy is a significant development and potential for LEDs (Ozluk, Muslu \& Arik, 2019). Their lifespan is due to their compact physical characteristics: LEDs are more durable than other lamps. Incandescent bulbs tend to last 1000 hours, as heat destroys the filament, and fluorescent lamps tend to last 10,000 hours. LEDs can last longer than 50,000 hours or more, and in turn they provide a wider color temperature range $(4500 \mathrm{~K}-12,000 \mathrm{~K})$ and a wider operating temperature $\left(20^{\circ} \mathrm{C}\right.$ to $\left.85^{\circ} \mathrm{C}\right)$ (Luo, Hu, Liu \& Kai, 2016).

However, there is no practical and accurate radiometric analysis to determine the actual light output that is emitted from LEDs. Light power influences optimal utilization of the amount of light that such a device is capable of generating. In some cases, the data provided by the manufacturer and the power measured in commercial radiometers do not match the power emitted by LEDs, measured with specialized or high-precision instruments (Price, Ferracane \& Shortall, 2015).

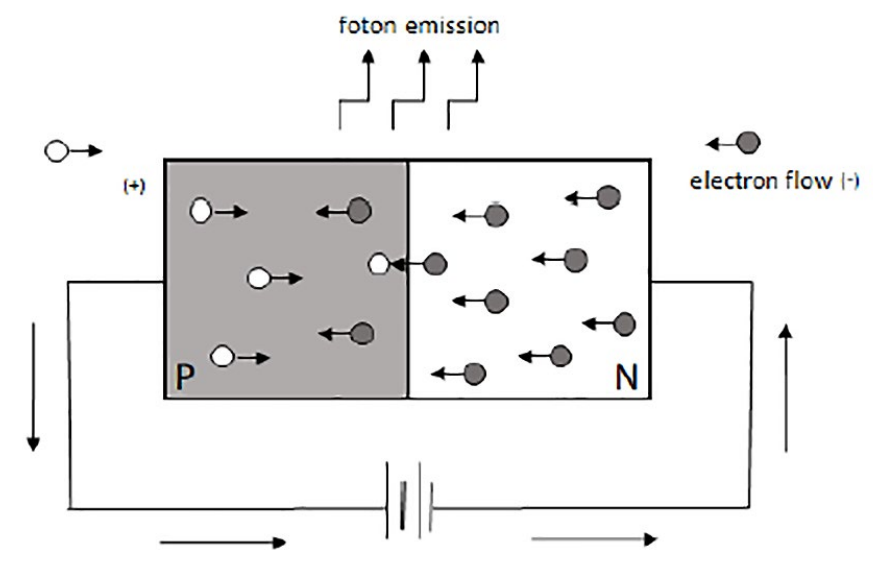

Figure 1. 1p-n joint configuration that occurs in light-emitting diodes Source: Adapted from [4]

The basic structure that allows the phenomenon of electroluminescence in the light-emitting diode is the $p-n$ joint. A $p-n$ joint is the union of two semiconductor materials, meaning, materials that are dielectric at rest but under certain conditions, are conductive. Semiconductor type and type 
materials are listed as extrinsic semiconductors, because they have been manipulated from their manufacture to favor a majority of positive and negative loads respectively. The $p-n$ joint allows an electric field to be form, as well as a potential difference; therefore, by connecting an electrical circuit to this joint, it will allow the passage of the current in the sense from positive to negative, specifically in terms of the device: from anode to cathode.

The $p-n$ joint configuration that occurs in light-emitting diodes is what is known by its English expression as forward bias. As shown in Figure 1, this configuration consists of the majority of carriers on both sides of the junction crossing the depletion zone and entering their opposite side of the joint, where they are minority carriers. The depletion zone is one that forms right at the intersection of the $p-n$ junction where both types of loads exist and is one that "separates" a material from another. Minority carriers then become present in the area of majority carriers of contrary cargo; this is known as the injection of minority carriers (Wilson \& Hawkes, 1998). These exceeds the results in the recombination of excitons, which are the pairs formed both of electrons and by the absence of these.

According to quantum theory, in energetic terms, when an exciton is recombined, it is because an electron has precipitated its energy. As is known, atoms of any material, in this case semiconductor materials, are related by covalent bonds. These bonds are represented in the orbitals or energy scales that occupy the electrons that make up that atom. When a free electron in the material precipitates its energy, it is moving from a driving state to a lower state of energy. In the case of recombination, the electron precisely takes up a space in the valence band or hollow to complete the number of electrons allowed in that energetic state. Because of this release of energy, the electron emits light.

Therefore, the objective of this type of $p-n$ joint in the emitting diodes is to force as much recombination as possible, that is, to find that most electrons can be recombined with so-called hollows so that this generation of energy can allow light emission continuously (Cabrera , López \& López, 2006).

LEDs have two basic properties: one is the luminous intensity and the other the transmitted optical power. The luminous intensity is the result of the flow of energy from a solid angle and is directly related to the illumination on a surface, generally used to express the brightness of an LED. On the other hand, the transmitted optical power indicates the total energy radiating from that device. The luminous intensity can be seen in Eq. (1):

$$
I=\frac{d \phi}{d \omega}
$$

Where $\omega$ is the spatial angle, and $\phi$ is the radiant flux or power, which can be given from the energy flow $\phi_{\mathrm{e}}$ as well:

$$
\phi_{e}=K_{m} \int_{380}^{780} V(\lambda) \phi_{e}(\lambda) d \lambda
$$


Where the standard luminosity curve is $V(\lambda), K_{m}$ is the maximum visibility and is approximately $683 \mathrm{~lm} / W$ to $\mathrm{a} \lambda=555 \mathrm{~nm}$.

The integral of the energy flow $\phi_{\mathrm{e}}$ in all propagation directions is the transmitted optical power $P t$, and is given by the following equation:

$$
P_{t}=\int_{A_{\min }}^{A_{\max }} \int_{0}^{2 \pi} \Phi_{e} d \theta d \lambda
$$

Where $A_{\max }$ and $A_{\min }$ are determined by the sensitivity curve of the photodiode (Komine \& Nakagawa, 2004).

The radiant flux or power called by the symbol $\phi$ is the measure of the power of energy that can be taken at any wavelength per unit of time. It includes infrared, ultraviolet, and visible light. The unit of measurement is Watt (W). Therefore, if you have a radiation source that has a radiant flow of $1 \mathrm{~W}$, you have that the source emits 1 Joule of energy for every second.

The radiant flow or power is described by the following expression:

$$
\phi=\frac{d \phi}{d t}
$$

The spectral distribution of the flow is required for the characterization of the response of a detector based on the incident energy. Since the spectral radiant flow or power, represented by $\phi \lambda$, is defined as the flow of energy radiating per unit of time and per unit of wavelength, it is measured in $\mathrm{W} / \mathrm{nm}$ as shown in the following expression:

$$
\phi_{\lambda}=\phi_{\lambda}(\lambda)=\frac{d Q_{\lambda}}{d t}=\frac{d \Phi}{d \lambda}
$$

It is necessary to note that when radiation affects a device that produces a signal such as voltage, proportional to the incident radiation, the total amount of the flow should be taken as magnitude instead of the flow per unit area; thus, you must specify the spatial extent of the radiation field whose flow is being considered (Gomez, 2006).

For the characterization of a radiation source, spectral irradiance $E \lambda$ considered a magnitude by describing the incident power that can be measured on an object at any wavelength. Spectral irradiance is a multivariate function of wavelength $\lambda$, which is position or angular distribution relative to the source that can beexpressed,$(r, \theta, \phi)$ in spherical coordinates or $(\mathrm{X}, \mathrm{Y}, \mathrm{Z})$ in a Cartesian system, $\mathrm{Z}$ is the direction of sym metry of the LED and finally of time $t$. Figure 2 describes the positions $(\mathrm{x}, \mathrm{y}, \mathrm{z})$ of the LED. 


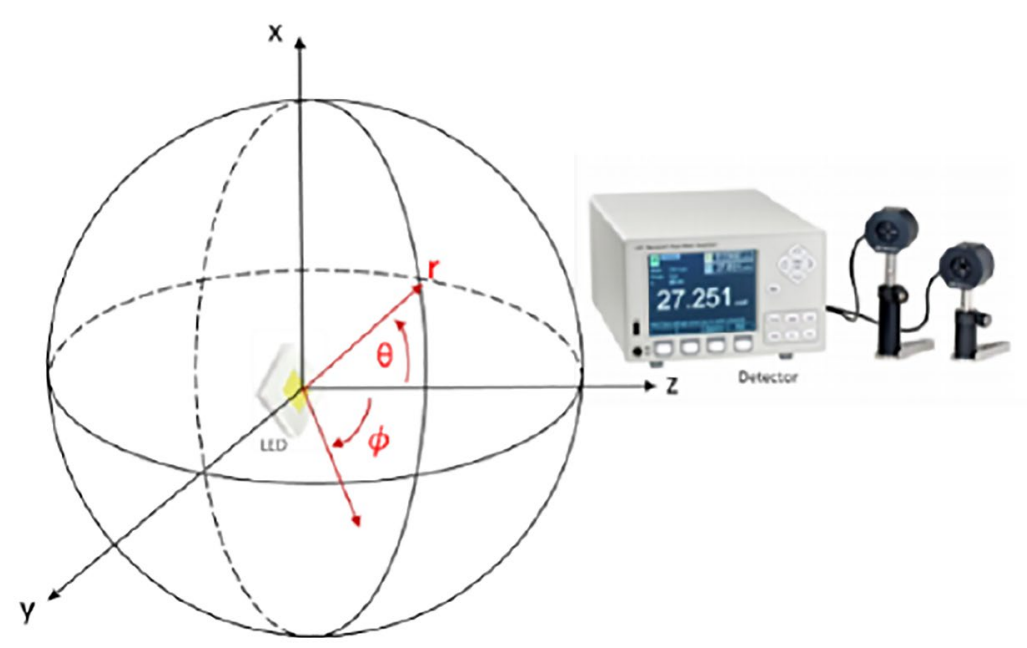

Figure 2. Cartesian plane in spherical coordinates for Positions $(\mathrm{x}, \mathrm{y}, \mathrm{z})$ for the distribution of spectral irradiance emitted by the LED

Different methods have been used in the existing literature to analyze the curve of the radiating flow emitted by LED. In the study developed by Mendoza, a method was implemented for the determination of the electric field model and the transverse oscillation mode of the beam of a laser. To obtain the necessary information, they obtained the power of the laser radiation, which was made through a circular aperture to which the radius could be varied (Mendoza \& Laboratorio de Tecnología Láser-ICTM, 2005). The author recommends positioning the detector close to the source to ensure that measurements are taken with the minimum radius of the laser beam and to ensure the measurement of the maximum power value. There are also other approximations of direct calculations in which the efficiency of radiation in the LEDs is studied for example, Magalhães et al. (2016) investigated the effect of different LED arrangements, placed on a disc with a diameter of 70mm and compared the different configurations such as: radial arrays, diamonds, square radials, and square diamonds. This study was conducted by optical simulation, in which the researchers concluded that square radial and radial matrices had better efficiency. This confirms that light efficiency,; the relationship between the luminous flux emitted by a light source and the power, has been improved by achieving greater output power due to phenomena such as the reflection of light and its redirection in the middle through the modification of the geometric shape LED (Jarosz, Marczynski \& Signerski, 2019; Tsai, Chen, Su \& Huang, 2010; Chen \& Wu, 2010; Chou, Chen \& Yang, 2012).

The objective of this project is to carry out the experimental evaluation of the effect of the spatial position on the power of a 5W LED and contribute to the characterization of this type of devices by detecting the power emitted using a radiometer. For this purpose, the measurement of the power of an LED was available through different distributions, which involve different positioning angles and variation of the distance of the LED from the detection equipment (Sholtes, et. al. 2019). The analysis of the obtained data for validation was performed with respect to the data in the manufacturer's specification sheet, which allows a comparison between the power or radiant flow emitted by the LED and the data provided by the manufacturer. Finally, it concludes which 
are the points of the greatest light power, determining the variation of the accuracy of the device according to the different distributions.

\section{DATA COLLECTION METHODOLOGY.}

\subsection{Materials}

The development of this study used a 5W power light-emitting diode (LED), brandOSRAM CSLPM1.TG, with a manufacturer-recommended power supply of $2.75 \mathrm{~V}$ to $3.5 \mathrm{~V}$ and a maximum current of 1.4A; a Radiometer (Power Meter), NEWPORT brand, Model 2936-R and an optical sensor, of the same brand, model 818-UV-L. In order to measure the power generated by the LED, a power source, ARRAY mark, reference 3631A, which powered the LED, two 360-degree continuous rotation goniometers (one THORLABS brand (vertical), reference PRM1, and another NEWPORT (horizontal), reference M-RSP- 2) were used to assemble the LED positioning system; in other terms, it performs the variation of the angles in the established two axes. Finally, a FLUKE multimeter, which allowed to visualize the ambient temperature, was also used. All these materials are found in the laboratory of the Group of Thin films and Nanophotonics of the Pontificia Universidad Javeriana of Bogotá.
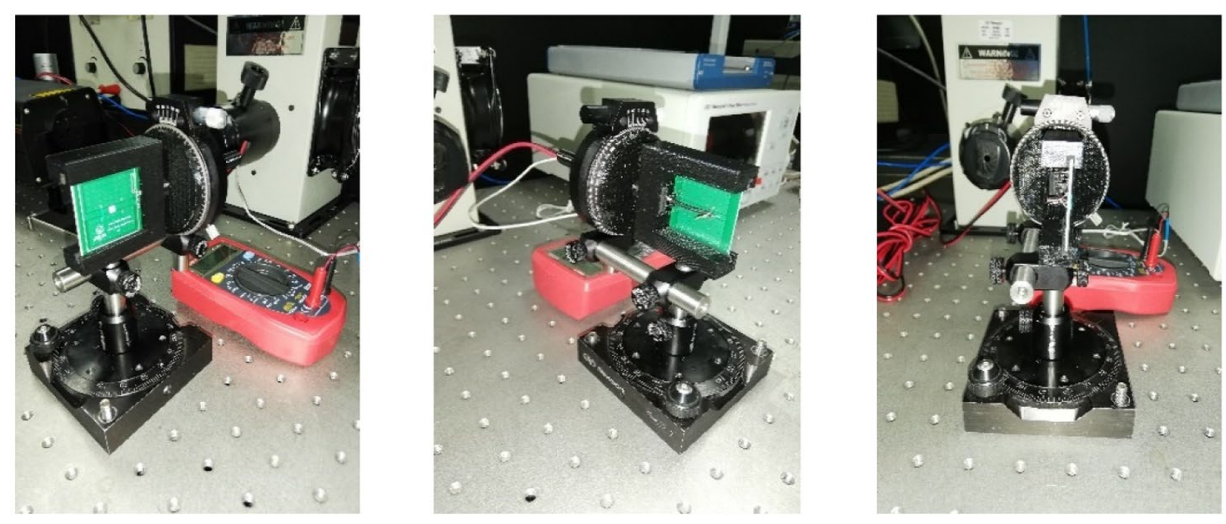

Figure 3. Prototype design at its different angles, used to position the LED

\subsection{Methods}

\subsubsection{Study factors}

The test consists of 3 factors: angle of variation on the $\mathrm{X}$ axis, angle of variation on the $\mathrm{Y}$ axis, and two distances on the $\mathrm{Z}$ axis between the LED and the detector.

The variation of the angles on both the $\mathrm{X}$ axis and the $\mathrm{Y}$ axis comprised 8 transitions since measurements were made from $0^{\circ}$ to $70^{\circ}$, every $10^{\circ}$. The distances considered for the $\mathrm{Z}$ axis were taken regarding two lengths between the LED and the detector: a short distance of $15 \mathrm{~cm}$ and a 
length of $30 \mathrm{~cm}$. Ten replicates were taken for each combination of X, Y, and Z. The study did not consider the angles of 80 and 90 degrees as they contained a blind spot in the measurement, and the power was zero.

\subsubsection{Experimental set up}

The mounting for LED power measurement was adapted on a flat and stable surface. Initially, the LED was positioned in front of the optical sensor and was fed with the source at $0.500 \mathrm{~A}$ and $3 \mathrm{~V}$, so these values did not exceed the maximums allowed by the manufacturer, preventing the heating of the LED, a factor that can affect the optimal operation of the device. The maximum power point was detected at position $0^{\circ} \mathrm{X}, 0^{\circ} \mathrm{Y}$ of the LED to ensure a correct alignment with the sensor, which collects the beam of light and connects to the Power Meter equipment that measures the power of the LED. In Figure 4, you can see the assembly made for the measurement of the power of the LED.

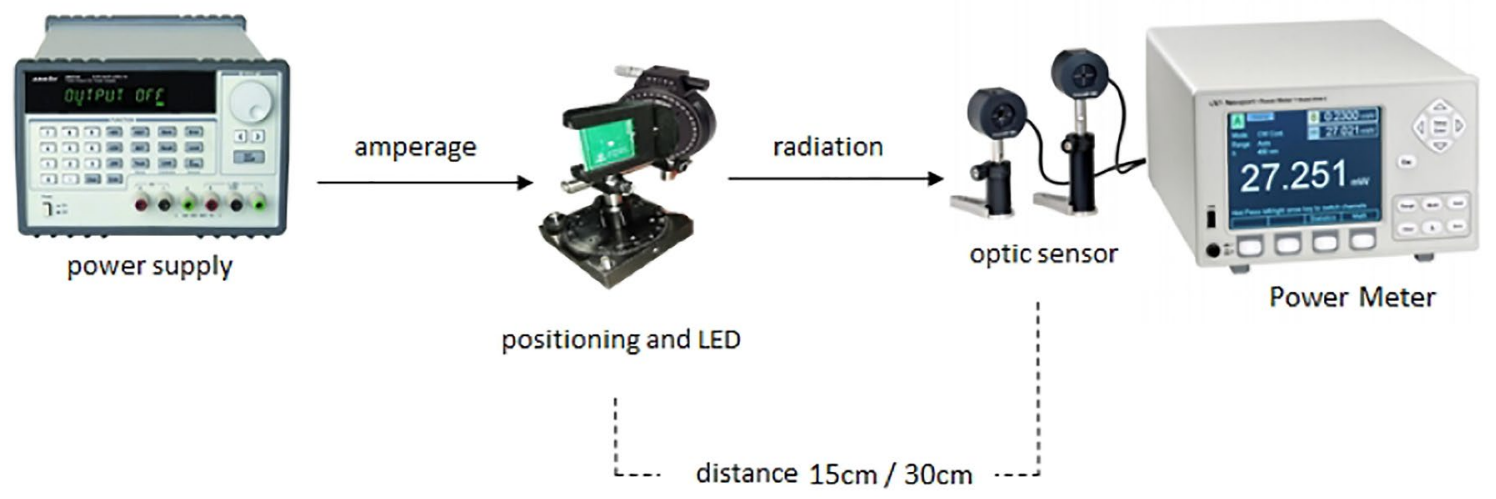

Figure 4. Schematic diagram made for measuring LED power

In addition, to ensure optimal environmental conditions during the experiment and to prevent external factors from affecting measurements, a controlled environment was required. For this purpose, a closed dark room was arranged, which did not allow the entry of external light. On the other hand, a multimeter was used with a thermocouple that allowed measuring the room temperature and ensuring that it remained in a range between $15-20{ }^{\circ} \mathrm{C}$. For experimental design, in order to have valid and objective conclusions, the response variable is the incident power of the LED per unit area in units of $m W^{*} \mathrm{~cm}^{-2}$. As for data collection, the taking of each of the samples was done randomly with a period of 3 minutes between each measurement to let the LED rest and make changes in angles and distances.

\section{RESULTS}

\subsection{Statistical analysis}

To perform the statistical analysis we used interaction plots of averages from the response observations. Finally, the statistical test used was a variance analysis (ANOVA) for a factorial design with 3 factors: the angle in X, the angle in Y, and the distances between the LED and the detector. 


\subsection{Descriptive analysis}

For descriptive analysis, data obtained from differences in factors from angles in $X, Y$ and distances regarding the incident power of the LED are presented.

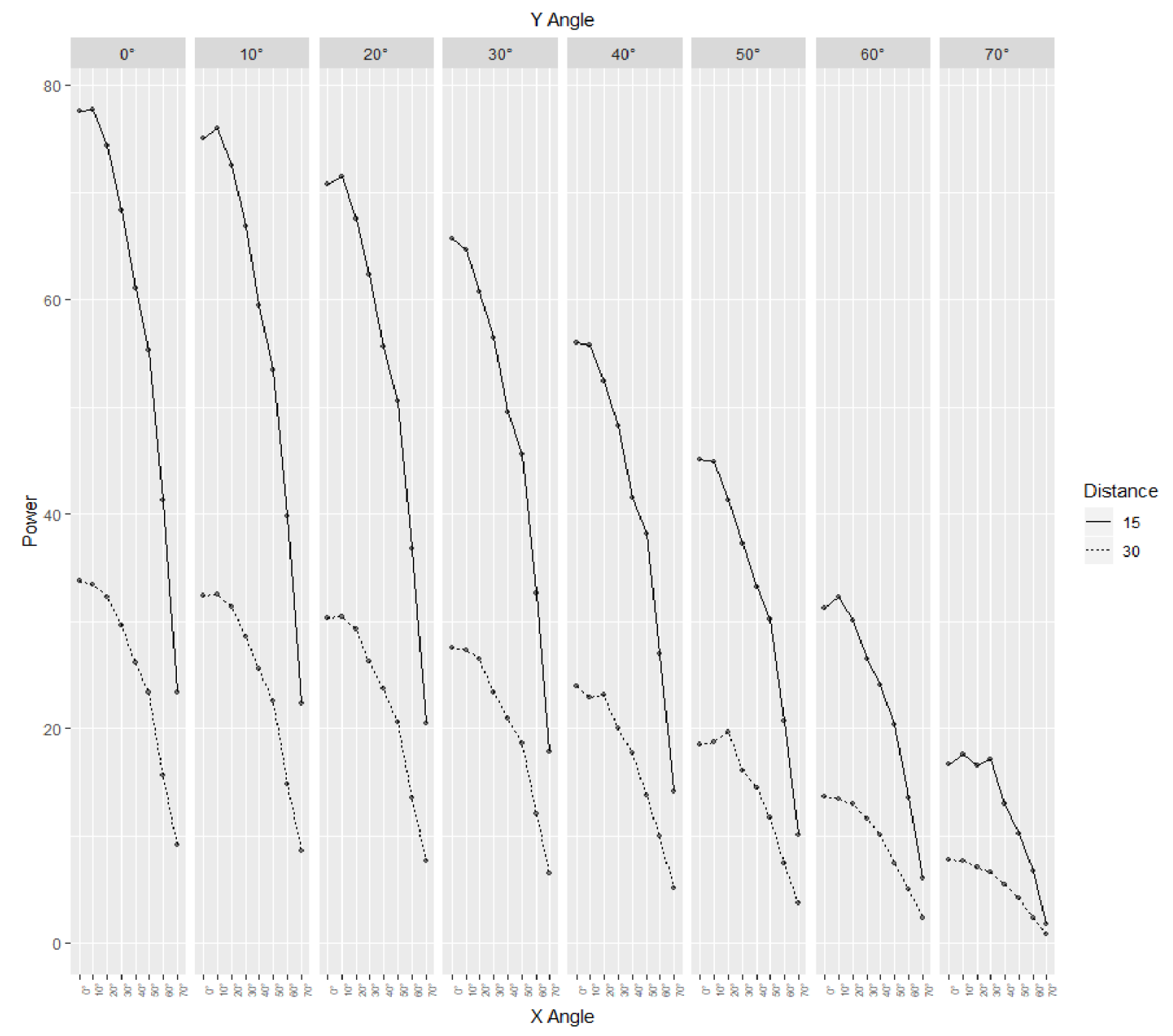

Figure 5. Average interaction graph of the 10 factor response observations

Figure 5 shows the construction of the average interaction plot of the 10 factor response observations, using the average of each treatment. It was possible to show that as the angle increases the averages decrease for both cases of distances; however, the averages obtained in the smaller distance have a greater variation. Through this chart, it was possible to observe that the power at a shorter distance and with smaller angles is greater.

By means of the inter-class influence chart (Figure 6), it was possible to supplement the information obtained in the previous graph. In this graph, you can observe through a color scale the averages of each treatment, which allows reiterating that the greater power is concentrated in the shortest distance and the smallest angles. 
15

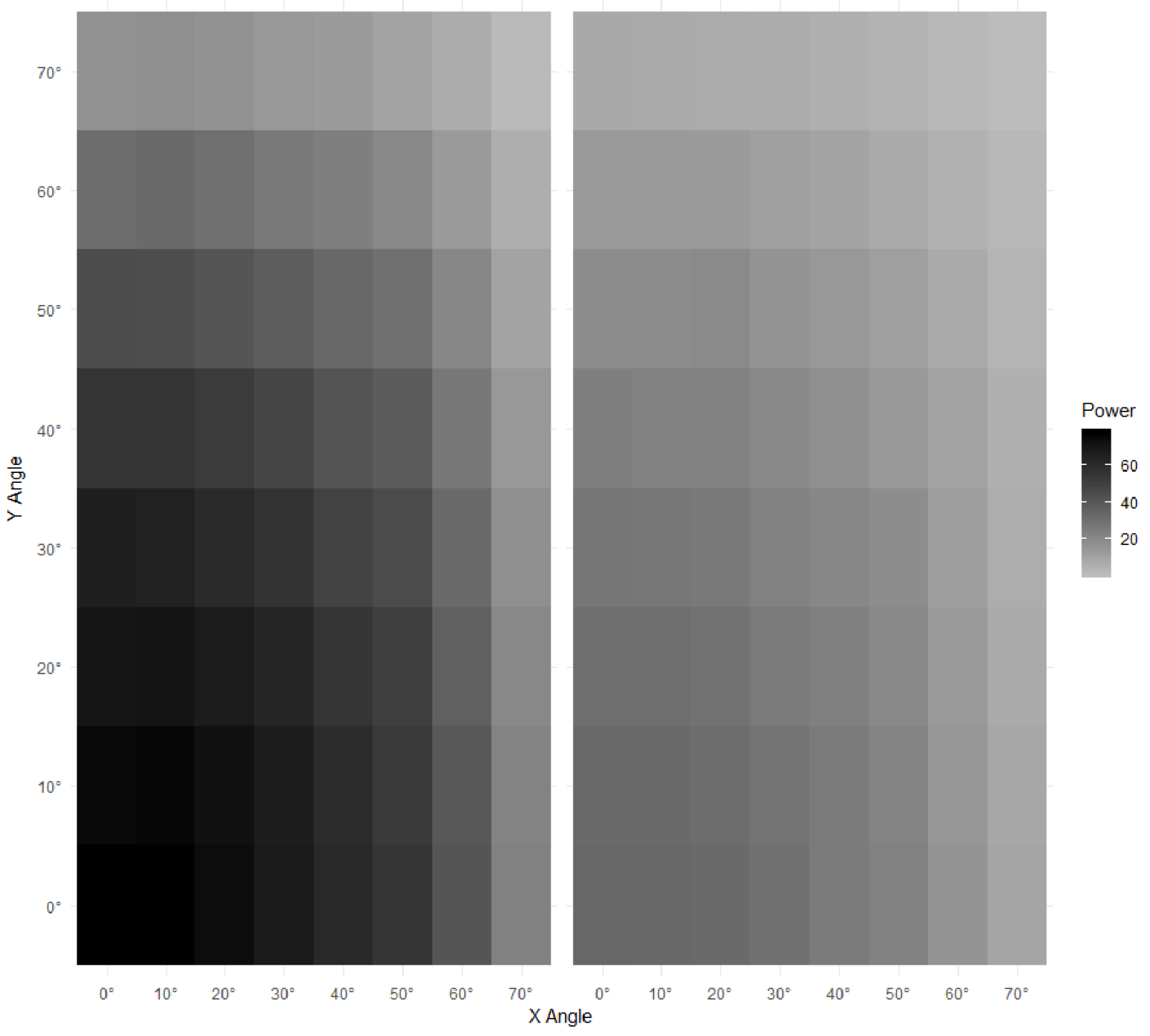

Figure 6. Inter-class influence graph
30

ower

40

20

\subsection{Proof of assumptions}

With this test, it was possible to confirm the assumptions of the ANOVA through graphical tests, demonstrating the randomness, independence, homogeneity of variances and the normality of the data. Kolmogorov Smirnov test for normality results showed $(p=0.23)$. Levene test for homoscedasticity showed ( $\mathrm{p}=0.42$, which confirms the population variances are equal among groups.

\subsection{Variance analysis}

The ANOVA variance analysis was used to examine the effects described above in the response variable, which for this case was the incident power of the LED. The results recorded in Table 1 
indicate that the p-value of the iteration between the factors was 0.4308 , so it is proved that it was statistically significant.

The results on Table 1 show that the factors had a significant effect on the response variable (p-value $<0.0001$ ). Using smaller angles and smaller distances increases the irradiated power of the LED as is shown in the previous chart. A Tukey-type Post-Hoc test was also used to know if statistically the three factors (X-angle, Y-angle, and distance) are different from power, demonstrating that $98 \%$ of classes are statistically different. However, some classes are statistically the same because their p-value is greater than $5 \%$.

Table 1. ANOVA Table

\begin{tabular}{cccccc}
\hline & \multicolumn{5}{c}{ ANOVA } \\
\hline & Df & Sum Sq & Mean Sq & F value & $\operatorname{Pr}(>\mathrm{F})$ \\
\hline Angle Y & 7 & 170067 & 24295 & 38982.99 & $<0.0001$ \\
Angle X & 7 & 123933 & 17705 & 28408.11 & $<0.0001$ \\
Distance & 1 & 186034 & 186034 & 298500.45 & $<0.0001$ \\
Angle Y - angle X & 49 & 12983 & 265 & 425.14 & $<0.0001$ \\
Angle Y - distance & 7 & 28071 & 4010 & 6434.47 & $<0.0001$ \\
Angle X - distance & 7 & 16987 & 2427 & 3893.81 & $<0.0001$ \\
Angle Y - angle X - distance & 49 & 1797 & 37 & 58.86 &
\end{tabular}

\section{DISCUSSION AND CONCLUSIONS}

This study assessed the effect of variation in the positioning of an LED with power. The results show that, according to existing research, the variation in positioning affects the distribution and uniformity of the factors of light emission including power, which increases the measurement error when there is greater distance and does not allow an optimal value of the power emitted by the light-emitting diodes. 
In addition, it is also necessary to take into account disturbances that can occur in the operation of the LED. This prevents its optimal performance such as the generation of harmonics, temperature variation, and voltage drops in the devices with flashing or flashing in the LED, affecting power and light intensity. ANOVA results shows that at greater distances $(30 \mathrm{~cm})$ their power values were low due to interference in the environment, This generated that the LED lighting created a diffraction of light, reducing its ability to penetrate and lowering its power.

In accordance with the results derived from statistical analysis, especially with the variance analysis, the research concluded that for the data taken at the distance of $15 \mathrm{~cm}$ there is a greater influence between classes, resulting in greater power emitted at the points between $0^{\circ}$ and $50^{\circ}$ of inclination. This makes it possible to determine that at a shorter distance $(15 \mathrm{~cm})$ there is a uniformity of emission, and a value of greater potential is detected, highlighting that the evaluation was done in a controlled environment based on the manufacturer's specifications so as not to alter the optimal performance of the device.

Finally, the power is correlated with the angle variation, since increasing the inclination of that factor decreases the power, having as a maximum point the value of $77.73 \mathrm{~mW}^{*} \mathrm{~cm}^{-2}$ for an angulation of $0^{\circ} \mathrm{X}, 0^{\circ} \mathrm{Y}$ of inclination and a minimum point of $0.86 \mathrm{~mW}^{*} \mathrm{~cm}^{-2}$. This determines that the detected power decreases by approximately $99 \%$ when there is a variation at larger angles.

\section{RECOMMENDATIONS AND FUTURE WORK}

In future work, other factors should be considered that could affect the optimal performance of the LED or other configurations that allow to optimize and that do not affect the data analysis of the response variable. It should be noted that the data obtained in the p-value for this study might have been affected by external factors that were not taken into account in this study such as the humidity of the environment and the fluctuations of the electrical voltage. Measurements for this study were taken only with an LED, but according to research conducted to increase the power emitted by the device, other factors besides the angles and distance can be added such as the number of LEDs that can form a matrix and its shapes.

\section{REFERENCIAS}

Cabrera , J., López, F., \& López, J. (2006). Optica Electromagnetica: Fundamentos (Segunda ed., Vol. I). Madrid: Universidad Autónoma de Madrid.

Chen, H.-C., \& Wu, G.-Y. (2010). Investigation of irradiance efficiency for LED phototherapy with different arrays. Optics Communications, 283, 4882-4886.

Chou, H.-Y., Chen, C.-C., \& Yang,T.-H. (2012). Maintenance of stable light emission in high power LEDs. Microelectronics Reliability, 52, 912-915.

Gomez, E. (2006). Guia basica de conceptos de Radiometria y Fotometria. Sevilla: Universidad de Sevilla.

Jarosz, G., Marczynski, R., \& Signerski, R. (2019). Effect of band gap on power conversion efficiency of single-junction semiconductor photovoltaic cells under white light phosphor-based LED illumination. Materials Science in Semiconductor Processing, 107, 1-5. doi:10.1016/j.mssp.2019.104812 
Komine, T., \& Nakagawa, M. (2004). Fundamental Analysis for Visible-Light Communication System using LED Lights. IEEE Transactions on Consumer Electronics, 50(1), 100-107. doi:10.1109/TCE.2004.1277847

Luo, X., Hu, R., Liu, S., \& Kai, W. (2016). Heat and fluid flow in high-power LED packaging and applications. Progress in Energy and Combustion Science, 1-32. doi:10.1016/j.pecs.2016.05.003.

Magalhães, T., Weig, K., Costa, M., Werneck, M., Barthem, R., \& Costa, C. (2016). Effect of LED-LCU light irradiance distribution on mechanical properties of resin based materials. Materials Science and Engineering C, 63, 301307. doi:10.1016/j.msec.2016.02.060

Mendoza, Omel; Laboratorio de Tecnología Láser-ICTM. (2005). Estimación de Modos TEMmn Laguerro-Gaussianos. Revista Cubana de Física, 22(2), 153-156.

Noori, A., Mahbub, P., Dvorák, M., Lucieer, A., \& Macka, M. (2018). Radiometric analysis of UV to near infrared LEDs for optical sensing and radiometric measurements in photochemical systems. Sensors and Actuators B: Chemical, 262, 171-179. doi:10.1016/j.snb.2018.01.179

Ozluk, B., Muslu, A. M., \& Arik, M. (2019). A Comparative Study for the Junction Temperature of Green LightEmitting Diodes. IEEE Transactions on Components, Packaging and Manufacturing Technology, 2024-2035. doi:10.1109/TCPMT.2019.2929172

Price, R., Ferracane, J., \& Shortall, A. (2015). Light-Curing Units: A Review of What We Need to Know. Journal of Dental Research, 94(9), 1179-1186. doi:10.1177/0022034515594786

Rigutti, L., \& Tchernycheva, M. (2013). Characterization of Semiconductor Heterostructures and Nanostructures. Torino: University of Torino. doi:10.1016/B978-0-444-59551-5.01001-3

Schubert, F., \& Kyu, J. (2005). Solid-State Light Sources Getting Smart. Science, 308, 1274-1278. doi:10.1126/ science. 1108712

Sholtes, K., Keliher, R., \& Linden, K. (2019). Standardization of a UV LED Peak Wavelength, Emission Spectrum, and Irradiance Measurement and Comparison Protocol. Environmental Science \& Technology, 53(16).

Tsai, P., Chen, W., Su, Y., \& Huang, C. (2010). Enhanced light output of InGaN LEDs with a roughened p-GaN surface using different TMGa flow rates in p-AlGaN layer. Applied Surface Science, 256, 6694-6698. doi:10.1016/j. apsusc.2010.04.072

Villamarín, A., Ferrero, A., Pons, A., Campos, J., Rabal, A., Hernanz, M., . . . Corróns, A. (2012). Angular and spectral radiant intensity distribution of high brightness white LEDs. Óptica pura y aplicada, 45(2), 131-136.

Wilson, J., \& Hawkes, J. (1998). Optoelectronics: An Introduction (Tercera ed.). Englewood Cliffs: Prentice Hall PTR. 